\title{
PRESSUPOSTOS PSICOLÓGICOS E DIDÁTICOS PARA A RESOLUÇÃO DE PROBLEMAS MATEMÁTICOS
}

\author{
PRESUPUESTOS PSICOLÓGICOS Y DIDÁCTICOS PARA LA RESOLUCIÓN DE \\ PROBLEMAS MATEMÁTICOS
}

\author{
PSYCHOLOGICAL AND DIDACTIC ASSUMPSIONS ON MATHEMATICAL \\ PROBLEM SOLVING
}

\author{
Fatima Aparecida Souza FRANCIOLI ${ }^{1}$ \\ Nilza Marcia Mulatti SILVA²
}

\begin{abstract}
RESUMO: Este artigo tomou como recorte as análises proferidas em uma pesquisa de mestrado na área de ensino e tem como objetivo apresentar os pressupostos psicológicos e didáticos referentes à resolução de problemas matemáticos. A pesquisa, de cunho teóricometodológico, discute as dificuldades dos alunos, dos anos iniciais do ensino fundamental, ao resolverem problemas matemáticos. Para tanto, apoiou-se nos estudos de Vigotski e Kalmykova para as questões psicológicas e estudos de Saviani para as questões didáticas. Os resultados apontaram que a solução de problemas exige que o aluno transcenda dos procedimentos descritivos para os explicativos e, assim, tome consciência de suas ações. Além de que o professor, ao valorizar o processo de resolução, ademais da resposta correta do problema, deve propor ao aluno a explicitação do procedimento realizado, favorecendo a mobilização de suas ideias e chegando ao pensamento por conceitos.
\end{abstract}

PALAVRAS-CHAVE: Vigotski e Kalmykova. Saviani. Ensino Fundamental. Subtração.

RESUMEN: Este artículo tomó como punto de referencia, los análisis manifestados en una investigación de maestría en el área de enseñanza y tiene como objetivo presentar los presupuestos psicológicos y didácticos referentes a la solución de problemas matemáticos. La investigación se basó en el modelo teórico-metodológico, discute las dificultades de los estudiantes, en los primeros años de la escuela primaria, para resolver problemas matemáticos. Para esto, se utilizaron los estudios de Kalmykova para la parte psicológica y los estudios de Saviani para las cuestiones didácticas. Los resultados apuntaron que la solución de problemas exige que el alumno trascienda de los procedimientos descriptivos a los explicativos y así tomar conciencia de sus acciones. Además, que el profesor, al valorar el proceso de resolución y la respuesta correcta del problema, debe proponer al alumno la explicación del procedimiento realizado, favoreciendo así, la movilización de sus ideas y llegando a un nivel de síntesis de análisis de conceptos.

PALABRAS CLAVE: Vigotski e Kalmykova. Saviani. Enseñanza Fundamental. Sustracción.

${ }^{1}$ Universidade Estadual do Paraná (UNESPAR), Paranavaí - PR - Brasil. Professora no Programa de PósGraduação Stricto Sensu, nível Mestrado Acadêmico em Formação Docente Interdisciplinar - PIPIFOR. Doutorado em Educação Escolar (UNESP). ORCID: https://orcid.org/0000-0001-8373-7056. E-mail: fas.francioli@hotmail.com

2 Universidade Estadual do Paraná (UNESPAR), Paranavaí - PR - Brasil. Professora e Coordenadora Pedagógica da Rede Municipal de Ensino de Alto Paraná. Mestrado em Formação Docente Interdisciplinar (UNESPAR). ORCID: https://orcid.org/0000-0003-3895-3029. E-mail: nmulatti29@hotmail.com

RIAEE - Revista Ibero-Americana de Estudos em Educação, Araraquara, v. 16, n. 4, p. 2648-2662, out./dez. 2021. e-ISSN: 1982-5587 DOI: https://doi.org/10.21723/riaee.v16i4.13612 
ABSTRACT: This article examines analyses from a master's research project in the field of education, aiming to present psychological and didact assumptions regarding mathematical problem solving. The research project, which is theoretical-methodological, discusses the difficulties of students, in the early years of elementary school, in solving mathematical problems. To that end, the researches of Vigotski and Kalmykova have been used for psychological and Saviani didactic matters, respectively. The results appoint that problem solving requires students to transcend from descriptive to explanatory procedures and thus become aware of their actions. Moreover, to better value problem resolution, teachers must propose that students explicit their process besides just providing the correct answers, favoring the mobilization of his ideas and arriving at thinking through concepts.

KEYWORDS: Vigotski and Kalmykova. Saviani. Elementary School. Subtraction.

\section{Introdução}

No trabalho da prática pedagógica, a relação ensino e aprendizagem faz parte de um processo contínuo entre professor e aluno. Para abordar esse processo o presente artigo tomou como recorte as análises proferidas em uma pesquisa de mestrado na área de ensino em que se discute as dificuldades dos alunos, dos anos iniciais do ensino fundamental, ao resolverem problemas matemáticos.

Muitos dizem que aprender matemática não é fácil, no entanto, a questão é buscar respostas para demonstrar como resolver alguns questionamentos: Por que alunos que sabem resolver os algoritmos muitas vezes não sabem aplicá-los para resolver os problemas matemáticos? Por que alguns alunos conseguem interpretar e outros não? Em busca dessas respostas, o presente estudo, tem como objetivo apresentar os pressupostos psicológicos e didáticos referentes à resolução de problemas matemáticos, com ênfase na subtração. De cunho teórico-metodológico, o estudo fundamenta-se em Vigotski e Kalmykova para as questões psicológicas e em Saviani para as questões didáticas.

Zinaida Ilinichna Kalmykova ${ }^{3}$ (1977), sob as bases da psicologia histórico-cultural, deu continuidade aos estudos desenvolvidos por Vigotski, em específico, na área da matemática com ênfase na aprendizagem e desenvolvimento. Dermeval Saviani (1997), autor brasileiro renomado por seus estudos na área das teorias e história da educação, definiu cinco categorias de conhecimentos que considera necessárias para o desenvolvimento do aluno: domínio do conteúdo curricular, conhecimento didático-curricular, saber pedagógico, condições sócio-históricas, saber atitudinal. Para Saviani, estas categorias estabelecem a dimensão do conhecimento que o professor precisa dominar para desenvolver um bom ensino.

${ }^{3}$ Colaboradora do Instituto de Psicologia da Academia de Ciências Pedagógicas da URSS (LURIA et al., 1977, p. 9).

RIAEE - Revista Ibero-Americana de Estudos em Educação, Araraquara, v. 16, n. 4, p. 2648-2662, out./dez. 2021. e-ISSN: 1982-5587 
A relação entre estes três autores está na estrutura filosófica materialista, em que estudam a educação escolar como promotora do desenvolvimento humano.

\section{Pressupostos psicológicos para a aprendizagem e resolução de problemas matemáticos}

Uma das respostas iniciais e que direcionou o caminho percorrido pela pesquisa baseou-se nas ideias de Dante (2008), que diz que o aluno somente conseguirá resolver problemas matemáticos se dominar os conceitos das operações de adição, subtração, multiplicação e divisão. Desta forma, buscou-se em Vigotski e Kalmykova a compreensão de como ocorre a apropriação de conceitos.

$\mathrm{Na}$ perspectiva da psicologia histórico-cultural a aprendizagem das crianças começa muito antes de elas frequentarem a escola, no entanto é por intermédio do ensino formal que os estudantes entram em contato com os conceitos organizados em diferentes áreas do conhecimento que compõem o currículo. Procuraremos, a partir desse ponto, definir a formação de conceitos.

Vigotski (2001), em seus estudos, põe em evidência as relações existentes entre os conceitos espontâneos e os conceitos científicos. Para ele, os conceitos espontâneos são aqueles formados pela comunicação direta com as pessoas com quem a criança convive, de forma livre, sem intencionalidade definida. Diferentemente, os conceitos científicos se desenvolvem por intermédio da mediação intencional e sistematizada, responsabilidade exclusiva da educação escolar. Vigotski (2001, p. 218) afirma que "os conceitos espontâneos possibilitam o aparecimento dos conceitos não espontâneos através do ensino" e que "a formação dos conceitos científicos na mesma medida que os espontâneos, não termina, mas apenas começa no momento em que a criança assimila pela primeira vez um significado ou termo novo para ela, que é veículo de conceito científico" (Idem, p. 265). Para o autor, não é pelo fato de o conteúdo ser abordado na escola que ele atinge o nível conceitual científico, mesmo sabendo que é função do ensino escolar proporcionar atividades capazes de transformar conceitos espontâneos em científicos, ou seja, transformar o pensamento espontâneo dos alunos em pensamento intelectual.

E como a criança se apropria dos conceitos? Antes de responder esta questão é preciso esclarecer que Vigotski (2001) dividi o percurso do pensamento em três grandes estágios básicos: pensamento sincrético, pensamento por complexo e pensamento por conceito. No estágio do pensamento sincrético, a característica principal é um emaranhado de ideias sem fundamento interno, mas ligadas à impressão que a criança tem das coisas; “[...] é a formação 
de uma pluralidade não informada e não ordenada, a discriminação de um amontoado de objetos vários no momento em que essa criança se vê diante de um problema" (VIGOTSKI, 2001, p. 175). Para o autor, o pensamento por complexo "conduz à formação de vínculos, ao estabelecimento de relações entre diferentes impressões concretas, à unificação e à generalização de objetos particulares, ao ordenamento e à sistematização de toda a experiência da criança" (Idem, p. 178). Assim, nesse estágio a criança começa a fazer as primeiras relações e apresenta como base o vínculo com o concreto entre os elementos. Começam, nesta etapa, as primeiras generalizações. Citamos como exemplo o ato de reunir peças de acordo com o atributo cor ou o atributo forma.

O último e almejado estágio a ser alcançado trata-se do pensamento por conceito.

[...] o conceito em sua forma natural e desenvolvida, pressupõe não só a combinação e a generalização de determinados elementos concretos da experiência, mas também a discriminação, a abstração e o isolamento de determinados elementos e, ainda, a habilidade de examinar esses elementos discriminados e abstraídos fora do vínculo concreto e fatual em que são dados na experiência (VIGOTSKI, 2001, p. 220).

Para além desse conceito, Vigotski (2001, p. 226) afirma que "o conceito surge quando uma série de atributos abstraídos torna a sintetizar-se, e quando a síntese abstrata assim obtida torna-se basilar de pensamento". Por meio dessa síntese, a criança percebe e toma conhecimento da realidade que a cerca. No entanto, "os conceitos não surgem mecanicamente como uma fotografia coletiva de objetos concretos" (VIGOTSKI, 2001, p. 237). A sua formação surge sempre no processo de solução de algum problema que se coloca no pensamento. O conceito surgirá da solução desse problema, portanto, dessa afirmação confirmamos a relevância do ato de problematizar os conteúdos escolares.

Para que ocorra o desenvolvimento dos conceitos científicos, são necessárias tarefas que possibilitem que o pensamento do aluno se volte mais para a atividade mental do que para o objeto sensorial. Nesse caso, a aquisição dos conceitos científicos percorre o caminho inverso dos espontâneos, desenvolvendo-se por um processo dedutivo das propriedades complexas e superiores às propriedades elementares e inferiores. Ou seja, as tarefas têm como ponto de partida a atividade mental, baseada na abstração de conhecimentos que promovem a apropriação do conceito. Ao atingir esse nível de pensamento conceitual, torna-se possível a relação desse conceito com os conhecimentos espontâneos, presentes nas experiências vivenciadas.

O domínio do ato do pensamento é revelador do nível de desenvolvimento psíquico do aluno, isto é, ele consegue converter suas funções psíquicas, como a percepção, a memória, a 
atenção voluntária e o próprio pensamento, em objetos da consciência. Significa, por assim dizer, que esse aluno se encontra em uma intensa atividade mental, plenamente ciente do processo de pensamento ao ponto de dominá-lo.

Nessa direção, em continuidade às pesquisas de Vigotski, Kalmykova (1977), como pesquisadora soviética, desenvolveu em meados do século $\mathrm{XX}$, juntamente com Leontiev, Luria, Zankov e outros colaboradores da psicologia histórico-cultural, diferentes estudos para contribuir com o trabalho dos professores e melhorar a aprendizagem das crianças dos anos iniciais do ensino fundamental. Para esta pesquisadora era fundamental investigar métodos de ensino utilizados por bons professores, comparando-os e observando sua eficácia na solução de problemas matemáticos.

De acordo com Kalmykova (1977), a solução de problemas exige muito mais do que conhecer os números e as técnicas operatórias, exige o conhecimento de diversos conceitos concretos e abstratos, que refletem as relações quantitativas entre os objetos. Por isso, para se resolver bem um problema, torna-se necessário haver sínteses em nível de análises complexas. Mesmo em um problema simples, os dados podem estar interligados de maneiras diversas, o que exige raciocínio elaborado para a resolução. Num problema composto, que necessita ser resolvido em mais de uma etapa, a escolha da operação a ser usada torna-se mais difícil, pois o aluno precisa escolher os números certos e definir suas possíveis combinações. "Esta análise preliminar é essencial para uma correta solução de problemas complexos" (KALMYKOVA, 1977, p. 10).

Outro apontamento importante, destacado por Kalmykova (1977), refere-se à afirmação de que, na formação de conceitos, quanto mais diversificado for o material concreto $^{4}$, mais fácil será o processo de abstração. Porém, reconhece a impossibilidade de realizar uma experiência sensorial com todos os materiais, por isso se devem priorizar aqueles que potencializam a ampliação do conceito estudado.

Kalmykova (1977) analisou a prática de uma das melhores professoras de uma escola de Moscovo, D.V. Petrova, professora da classe I. Pelos relatos apresentados, há indícios de que se trata do primeiro ano do ensino fundamental. Dentre suas observações, a autora destaca que, mesmo antes de as crianças começarem a ler e a aprender os primeiros conteúdos matemáticos, a professora disponibilizava a elas uma diversidade de materiais e objetos não

\footnotetext{
${ }^{4}$ Kalmykova (1977) usa o termo "material concreto", porém, nas tarefas de intervenções usaremos o termo "material manipulável", pois para Marx, base filosófica que fundamenta o presente estudo, o abstrato e o concreto não existem em separado; fazem parte de uma totalidade, de uma unidade, o concreto é dado pelo pensamento, é o concreto pensado.
} 
escolares. Esses materiais concretos, segundo a autora, facilitavam a transição para a abstração ao conceito de número, de operações matemáticas e de problemas.

Outro encaminhamento relevante observado pela autora e realizado pela professora Petrova refere-se à utilização de desenhos como meio de consolidar o conteúdo. Por exemplo, o número 5 era relacionado pela professora com cinco objetos, a professora orientava a criança, visando que esta não formasse uma única conexão específica, ou seja, relacionar a palavra 5 somente com essa quantidade de objetos concretos. Podemos inferir, com Kalmykova (1977, p. 16), que o direcionamento deve basear-se na diminuição gradativa do número de objetos e de signos, passando a usá-los somente para introduzir novos conceitos, ou, quando for necessário, "constituir e consolidar conexões". A autora orienta também que, para encaminhar as crianças à generalização, podemos fazer uso de imagens, pois elas se baseiam na realidade concreta, mas não são essa realidade.

Kalmykova (1977) orienta que o trabalho eficiente sobre a formação de conceitos não se reduz aos primeiros estudos, mas se prolonga por todos os anos de escolarização. Nesse sentido, consideramos correto o fato de o conceito de subtração iniciar-se na educação infantil e se estender ao ensino fundamental, pois a apropriação não ocorre de forma pontual e completa de uma só vez.

Outro direcionamento que consideramos importante em relação à análise dos erros refere-se à atenção necessária sobre a forma de pensar dos alunos e aos conceitos essenciais para se compreender determinado conteúdo escolar. Destacamos as mediações para fazer o aluno reconhecer o erro, pensar em "por que" errou, mudar sua resposta e reconhecer o acerto. Portanto, não basta mostrar o erro e corrigir as respostas dos alunos. Somente considerar o erro como parte do processo não provoca avanços na aprendizagem. Os avanços advêm da análise realizada pelo aluno, por intermédio da mediação do professor, que percebe que a resolução realizada não condiz com a lógica da atividade proposta.

Nas classes mais avançadas, denominadas de classe II e III, que podem ser comparadas ao segundo e terceiro anos do ensino fundamental, a professora introduziu esses conceitos, solicitando aos alunos que traduzissem o texto do problema matemático em termos mais abstratos. Foi solicitado que expressassem de modo correto os dados e o valor procurado, o que exigiu uma linguagem científica. Na classe IV, Kalmykova relata que a professora começou a acostumar as crianças a se expressarem em termos matemáticos apropriados não somente no conteúdo do problema, mas também em sua solução. Ela orientava pouco a pouco os alunos a deixarem a imagem visual e passarem para a abstração, a 
fim de que eles assimilassem as "categorias matemáticas mais complexas" (KAMYKOVA, 1977, p. 20).

Tecidas essas considerações, a autora esclarece que num primeiro momento nem todos os alunos assimilam, mas por intermédio do trabalho sistemático do professor sobre esses conceitos todos se tornam capazes de aprender. Portanto, o trabalho sistematizado sobre os pressupostos da psicologia histórico-cultural capacita para a aprendizagem não somente os bons alunos, mas todos os envolvidos no processo. Em razão de que as reflexões e as proposições, expressas na teoria, apresentam-se enquanto possibilidades para a realização de procedimentos e recursos didáticos ricos de significado e devem figurar como características essenciais no processo de ensino.

Voltamos aos questionamentos iniciais que norteiam este texto: Por que alunos que sabem resolver os algoritmos muitas vezes não sabem aplicá-los para resolver os problemas matemáticos? Por que alguns alunos conseguem interpretar e outros não? Em busca dessas respostas, torna-se relevante considerarmos que

[...] o trabalho de formação dos conceitos necessários para resolução de problemas é um meio para aumentar a eficácia da atividade analíticosintética. Mas a assimilação dos conceitos e das correspondentes leis matemáticas não implica uma habilidade especial para resolver problemas mais complexos. Não basta possuir noções; é necessário ser capaz de as usar no momento preciso, escolhendo as noções necessárias para a solução de determinados problemas. Costuma suceder que um aluno não consiga resolver um problema por não saber mobilizar as noções que possui. A escolha das noções necessárias exige uma especial concentração sobre o texto do problema, ou seja, analisá-lo (KALMYKOVA, 1977, p. 20-21).

Nesse sentido, consideramos que, para se conseguir interpretar e resolver um problema matemático, além de aprender os conceitos das operações, dos termos matemáticos e dominar a resolução das operações, é preciso saber mobilizar esses conhecimentos e usá-los adequadamente.

Kalmykova (1977) adverte que a pressa em consolidar o hábito de resolver problemas e a falta de um tempo maior para explicar detalhadamente o processo de resolução dos problemas provocam nos alunos certa lentidão de raciocínio. Como não conseguem recordar o raciocínio que conduz à solução, também não conseguem transpor o método usado para resolver certo tipo de problema para outro problema. Portanto, é necessário dar ênfase ao método utilizado para resolver os problemas, dispondo de um tempo considerável para as análises. A autora confirma que: 
[...] uma assimilação consciente dos métodos de resolução de problemas não só exige que se assimile o correspondente sistema de operações aritméticas, como também que se assimile a forma do raciocínio mediante a qual os alunos analisam o conteúdo de um problema e escolhem determinadas operações (KALMYKOVA, 1977, p. 24).

Essa afirmação vem ao encontro de nossa investigação, no que se refere à importância de se dedicar uma atenção especial aos métodos de ensino da análise dos problemas e ao raciocínio durante esta análise, ou seja, compreender as fases que o pensamento percorre até o pensamento por conceitos. Nesse sentido, podemos afirmar que o professor precisa receber uma formação que abranja não somente conteúdos específicos da área, como também conteúdos relacionados a metodologias.

\section{Pressupostos didáticos e a análise das manifestações da linguagem dos alunos na resolução de problemas matemáticos}

Conforme discutido acima, na relação professor-aluno reside o aspecto fundante da educação escolar como mediadora entre o ensino e a aprendizagem. Isso pressupõe um trabalho educativo que na visão de Saviani (1977) deve ser intencional e produzir em cada aluno o conhecimento historicamente desenvolvido pela humanidade.

Nessa direção, Saviani (1997), ao elencar os conhecimentos necessários para produzir conhecimento no aluno, define cinco categorias de conhecimentos relevantes para o trabalho do professor.

A primeira categoria definida por Saviani (1997) parece óbvia, pois se refere ao “domínio do conteúdo curricular", todavia é uma categoria que precisa ser consolidada. Vale ressaltar que não importa o nível de atuação, o professor obrigatoriamente deve conhecer amplamente o conteúdo a ser ensinado, por isso precisa dominar os conceitos. Conhecer o conteúdo é o primeiro passo, por sinal muito importante, mas não o suficiente para transmitir o conhecimento para o aluno. A segunda categoria definida por Saviani (1997) refere-se ao "conhecimento didático-curricular"; enfatiza que é preciso saber como organizar os conteúdos. Saviani (1997, p. 131) define que os conhecimentos precisam ser "dosados, sequenciados e trabalhados na relação professor-aluno". O autor afirma que essas duas primeiras categorias são consideradas as modalidades básicas para o professor ensinar com eficiência. Saviani (1997) faz essa distinção para enfatizar a necessidade de o professor se apropriar do saber pedagógico produzido pela ciência da educação, conhecer as teorias pedagógicas que embasam as políticas educacionais e que influenciam de forma expressiva a 
prática docente. A terceira categoria refere-se ao "saber pedagógico", ou seja, os conhecimentos produzidos pela ciência da educação.

Não dá para conhecer a escola estudando somente a escola, pois a educação está inserida em um contexto em que sofre diretamente as influências da situação socioeconômica e cultural. Assim, a quarta categoria trata da compreensão das "condições sócio-históricas" que determinam a tarefa educativa, conhecimentos imprescindíveis para pensar na formação crítica, pois a criticidade perpassa o conhecimento da totalidade.

A quinta categoria inclui o "saber atitudinal", responsável por estabelecer coerência entre o saber e o fazer. Como diz o autor, não se trata de confundir profissão com missão, mas de se adotar uma postura ética. Refere-se às atitudes e posturas próprias da função atribuída ao professor, definidas por Saviani (1997, p. 136) como "disciplina, pontualidade, coerência, clareza, justiça e equidade, diálogo, respeito às pessoas dos educandos, atenção às suas dificuldades, etc." Segundo o autor, essa competência está relacionada à identidade e à personalidade do professor, mas que são objetos de formação.

Saviani (1997) define, por intermédio das categorias anteriormente apresentadas, a dimensão do conhecimento que o professor precisa dominar. Nossa posição é a de que a ausência de conhecimento em alguma dessas categorias afeta a eficácia do ensino e compromete a possibilidade de o aluno apreender o conhecimento histórico socialmente produzido pela humanidade.

É preciso, pois, que a partir desses pressupostos didáticos, o professor adote em sua prática situações de ensino e aprendizagem cuja riqueza permita a apropriação do conhecimento científico. Nesse estudo nos referimos à resolução, em sala de aula, de problemas matemáticos.

Perante as dificuldades apresentadas na interpretação matemática em resolver problemas matemáticos, conferida em salas de aulas, e da hipótese de que os alunos realizam as operações, resolvem os algoritmos, mas não têm consciência da ação que realizam, ou seja, não se apropriaram dos conceitos científicos, foi desenvolvido um trabalho pedagógico ${ }^{5}$, relativo à aprendizagem do conceito da subtração, que envolveu crianças ${ }^{6}$ de nove a onze anos, matriculadas no quarto ano do ensino fundamental de uma escola da rede municipal localizada no noroeste paranaense. O propósito foi conhecer o nível de consciência da ação de

${ }^{5}$ Para ter acesso à pesquisa. Disponível em:

http://ppifor.unespar.edu.br/files/NILZA_MARCIA_MULATTI_SILVA.pdf. Acesso em: 10 jun. 2021.

${ }^{6}$ Segundo o ECA - Estatuto da Criança e do Adolescente (BRASIL, 2002), é considerado criança o cidadão que tem até 12 anos incompletos.

RIAEE - Revista Ibero-Americana de Estudos em Educação, Araraquara, v. 16, n. 4, p. 2648-2662, out./dez. 2021. e-ISSN: 1982-5587 
subtrair, por intermédio da análise da manifestação das linguagens oral, desenhos e manipulação de objetos.

O trabalho pedagógico relatado a seguir faz parte de uma sequência de atividades realizadas, dentre elas, inclui-se a retomada dos conteúdos referentes a subtração, intervenções que antecederam a tarefa solicitada aos alunos envolvendo resolução de problemas similares, dentre outras ações. Relataremos a seguir três momentos das aulas, considerados importantes para analisar a possível ação consciente ao resolver problemas matemáticos: justificativa oral da escolha da operação matemática, representação por intermédio de desenho e ilustração usando material manipulável.

No primeiro momento foi entregue um problema a cada aluno e foi solicitado que respondessem qual a operação matemática que poderia usar para resolvê-lo e principalmente que, justificassem o motivo da escolha, ou seja, o foco principal não estava na resposta certa do problema, mas na explicitação do pensamento envolvido na resolução.

As justificativas orais obtidas foram de vários níveis, como pode-se verificar por intermédios dos relatos a seguir: "Resolve através da adição porque tem que fazer conta"; "Divisão porque vai colocar no saquinho"; "É de adição porque vai juntar as páginas que leu com as que ela não leu"; "Subtração porque eu retiro"; "Subtração porque 'faltam' para completar o álbum". Houve também alunos que não conseguiram explicar a sua escolha, outros confundiram os nomes das operações, não reconheceram o termo "diferença" como resultado da subtração, além de nomearem a operação de adição como "continha de mais" e a operação de subtração como "continha de menos". Essa ausência do uso da nomenclatura correta nos remete ao fato de a escola, por vezes, reforçar os conhecimentos espontâneos relacionados à nomenclatura dos algoritmos. Observamos, nos alunos que apresentaram desempenho melhor na realização das tarefas, a utilização precisa da nomenclatura das operações.

A partir da constatação da dificuldade em explicitar o procedimento usado para resolver problemas, e a defesa de Kalmykova (1991) de que o desenho seria um ponto intermediário entre o concreto e o abstrato, sendo necessário recorrer ao material visual como base na formação de conceitos para não se deter somente na assimilação puramente formal das noções, optou-se por acrescentar, no segundo momento, o desenho como outra forma de expressão, além do algoritmo, como meio de consolidar o conteúdo.

Nesse segundo momento, a fim de aprimorar a análise da apropriação dos conceitos das operações, através da ação consciente, foram retomados seis problemas do momento anterior, resolvidos usando a subtração. A tarefa consistia em realizar a operação e desenhá-la 
identificando seus termos, ou seja, o minuendo, o subtraendo e o resto ou a diferença. Ao desenhar, o aluno precisou pensar sobre o que representava cada número usado no algoritmo e relacioná-lo ao problema proposto.

Dentre os problemas, foi escolhida a representação da aluna $\mathrm{Amanda}^{7}$, que envolve a ideia de comparar da subtração, para o seguinte problema: "Kaike tem oito anos e sua irmã, Thaila, tem 14 anos. Quantos anos Thaila têm a mais do que Kaike?"

Figura 1 - Representação da solução do problema

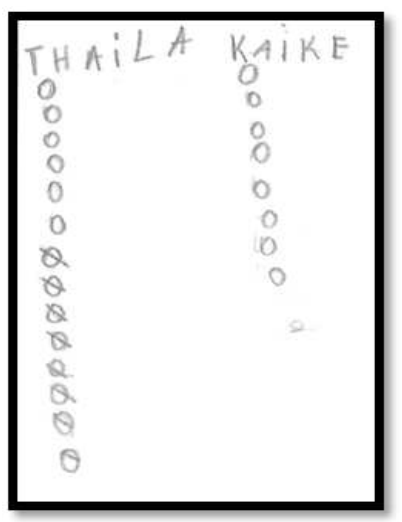

Fonte: A autora (2015)

Ao observar o desenho acima e com base na explicação oral, a aluna representou o minuendo e o subtraendo através de círculos irregulares, e o ato de subtrair, traçando um risco sobre eles. Percebe-se que não há relação explícita entre o minuendo e o subtraendo. Ao ser questionada onde está representada a diferença da idade entre Kaike e Thaila, ela explica: "Aqui tem oito e aqui tem quatorze". A aluna conhece o significado da palavra, mas não identifica em seu desenho, o termo "diferença" como resultado da operação de subtração.

O desenho como forma de linguagem, favoreceu substancialmente a expressão do pensamento, confirmando a defesa de Kalmykova (1991) de que o desenho não é o problema real, mas expressa a realidade pensada pelo aluno, e por ser a manifestação externa do pensamento, pode vir a ser o ponto de partida para a abstração.

Mesmo tendo esses pontos positivos, durante o desenvolvimento das tarefas, foi verificado que os alunos apresentaram dúvidas relacionadas à maneira como desenhar o ato de retirar. Dúvidas pertinentes, pois, se eu retiro, como pode permanecer? Desenhar foi um recurso a mais, porém a ação do retirar ainda ficou comprometida. Essa situação nos remete à afirmação de Kalmykova (1991, p. 12) de que “a base psicológica necessária para uma correta

${ }^{7}$ Os nomes dos alunos são fictícios.

RIAEE - Revista Ibero-Americana de Estudos em Educação, Araraquara, v. 16, n. 4, p. 2648-2662, out./dez. 2021. e-ISSN: 1982-5587 DOI: https://doi.org/10.21723/riaee.v16i4.13612 
formação dos conceitos é uma assimilação que permita criar condições entre as componentes abstratas e concretas do pensamento, entre a palavra e a imagem".

No terceiro momento, o grupo era composto por seis alunos e foram utilizados materiais manipulados, por dois motivos: devido à dificuldade dos alunos em desenhar a “ação de retirar", e à afirmação de Kalmykova (1991) de que, na formação de conceitos, quanto mais diversificado for o material concreto, mais fácil será o processo de abstração.

Para esse fim, foram escolhidos dois problemas para que os alunos representassem a operação de subtração, dentre eles, o problema do momento relatado anteriormente. A tarefa consistiu em representar a ideia de comparar da subtração. A idade da Thaila foi representada por canudinhos, e a idade do Kaike, por palitinhos de picolé.

Anteriormente à resolução da tarefa, foi explicado que, para resolver o problema, poderiam usar a subtração: quatorze menos oito é igual a duas patas (14-8=6). Solicitou-se que fizessem a operação, usando os palitinhos e canudinhos, e respondessem à pergunta: $\mathrm{O}$ que representa o número 8 , o subtraendo?

A resposta esperada, e que fundamenta a ideia de comparar do conceito da subtração, é que, ao comparar, retiramos a quantidade que o minuendo e o subtraendo têm em comum. Quando comparamos quantidades, o subtraendo representa a quantidade comum entre subtraendo e minuendo, nesse caso, o número 8 representa a idade em comum entre Thaila e Kaike.

Todos os alunos representaram corretamente a tarefa solicitada, porém, 1/3 dos alunos conseguiram relatar o procedimento realizado, mas não conseguiram justificá-lo. A seguir, serão apresentadas duas tarefas resolvidas, em que há indícios de ação consciente.

Figura 2 - Representação do problema pelo aluno Carlos

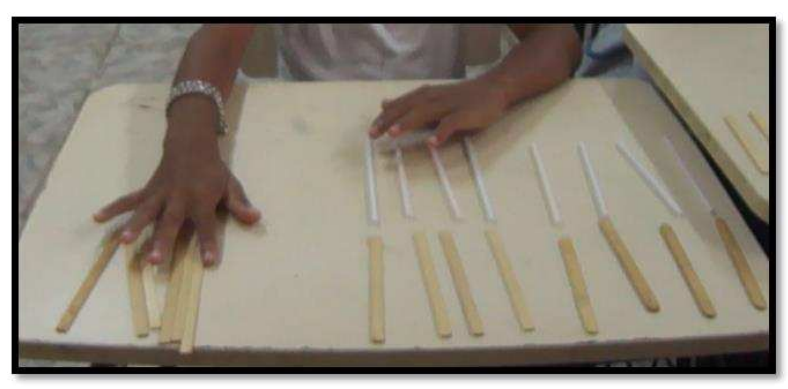

Fonte: A autora (2015) 
Explicação do Carlos: "Eu coloquei os 14 palitinhos, aí eu coloquei os oito canudinhos embaixo, aí eu tirei esses oito. Esses canudinhos é a idade do Kaike. Esses palitos são da Thaila. A gente tira o que tem de igual e sobra a diferença".

Figura 3 - Representação do problema pelo aluno Breno

Fonte: A autora (2015)

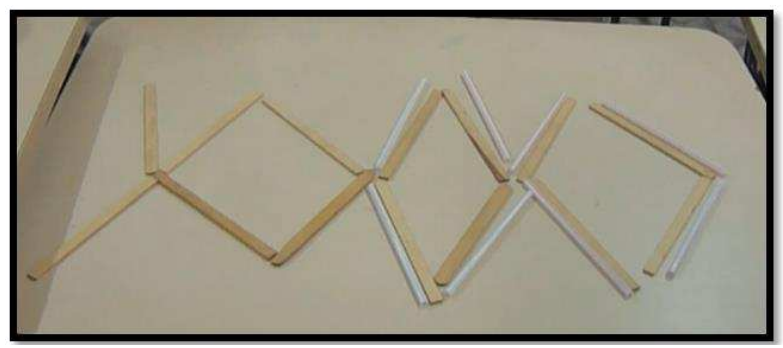

Explicação do Breno: "Eu fiz a idade da Thaila com os palitos e depois eu fiz a idade do Kaike com os canudos e deram esses dois triângulos (na verdade quadriláteros irregulares) e sobraram esses que deu seis. Até aqui é o que eles têm de igual e o resto é a diferença."

Ao finalizar a tarefa, verificou-se que os alunos Carlos e Breno resolveram de forma correta, conseguiram explicar "o que" e "por que" fizeram a representação da operação de subtração, usando os canudinhos e os palitos. Fabieli não realizou a representação de forma correta, mas conseguiu explicar "o que" fez. Pode-se considerar um avanço. Amanda fez de forma correta, conseguiu explicar "o que" fez, mas não "por que" fez. Everton e Daniele fizeram de forma correta, mas tudo indica que imitaram a realização da tarefa feita pelo Carlos e não conseguiram explicar nem mesmo "o que" fizeram. Dessa análise, pode-se inferir que Carlos e Breno têm consciência da ação de subtrair, Fabieli e Amanda estão em processo, sendo que Fabieli não resolveu corretamente, mas conseguiu explicar, por essa razão consideramos que ela está desenvolvendo o conceito. Ao verbalizar o procedimento, ela analisará a resolução e pode tomar consciência do seu erro. A Amanda resolveu a tarefa, mas não conseguiu explicar. Nesse momento da análise da tarefa verificou-se que há indícios de que os alunos estão em processo de aprendizagem do conceito da subtração, mas não conseguem chegar à abstração e à generalização, tão necessárias à formação do conceito científico. Pois, em Vigotski (2001, p. 226), "o conceito surge quando uma série de atributos abstraídos torna a sintetizar-se, e quando a síntese abstrata assim obtida torna-se basilar de pensamento". 


\section{Considerações finais}

Os dados da pesquisa demonstraram a dificuldade dos alunos em explicitar o procedimento usado ao resolver as tarefas propostas. No entanto, para Kalmykova (1991), a solução de problemas exige muito mais do que conhecer os números e as técnicas operatórias, ou seja, é necessário que o aluno se aproprie dos conceitos concretos e abstratos, chegando a sínteses em nível de análises complexas.

Nos anos iniciais, além da linguagem oral e escrita ou numérica o desenho pode ser utilizado como forma de expressão, além do algoritmo, assim, como confirma a defesa da autora ao dizer que as imagens representam o concreto, mas não são o concreto. Isso significa que a utilização do desenho, como procedimento didático, é um ponto intermediário entre o concreto e o abstrato, como também o ponto de partida para a abstração. O desenho representa a manifestação externa do pensamento que, ao ser transposto para o pensamento da criança, foi por ela interpretado abstratamente. A criança, ao captar empiricamente o objeto analisado, reproduz em seu pensamento a dinâmica e a estrutura desse objeto.

No que se refere aos procedimentos didáticos, às categorias pedagógicas defendidas por Saviani (1997) quando enfatiza o domínio dos conhecimentos pelo professor, precisam estar elencados aos bons materiais a ser utilizados, às formas de linguagem, às tarefas desenvolvidas pelos alunos e ao contexto em que os alunos estão inseridos, considerando que as privações culturais e econômicas afetam a aprendizagem.

Consideramos que a resolução de problemas, em diversos momentos da aula, pode apresentar respostas corretas de forma implícita, mas não é a compreensão da ideia da operação usada para a resolução do problema. O professor, ao valorizar o processo de resolução, além da resposta correta do problema, deve propor ao aluno a explicitação do procedimento realizado, favorecendo a mobilização de suas ideias.

\section{REFERÊNCIAS}

DANTE, L. R. Aprendendo sempre: matemática. São Paulo: Ática, 2008.

KALMYKOVA, Z. I. Pressupostos psicológicos para uma melhor aprendizagem da resolução de problemas aritméticos. In: LURIA, A. et al. (Org.). Pedagogia e psicologia II. Lisboa: Estampa, 1977. p. 9-26.

SAVIANI, D. A função docente e a produção do conhecimento. Educação e Filosofia, Uberlândia, v. 11, n. 21, p. 127-140, 1997. 
VIGOTSKI, L. S. A construção do pensamento e linguagem. 1. ed. São Paulo: Martins Fontes, 2001.

\section{Como referenciar este artigo}

FRANCIOLI, F. A. S.; SILVA, N. M. M. Pressupostos psicológicos e didáticos para a resolução de problemas matemáticos. Revista Ibero-Americana de Estudos em Educação, Araraquara, v. 16, n. 4, p. 2648-2662, out./dez. 2021. e-ISSN: 1982-5587. DOI: https://doi.org/10.21723/riaee.v16i4.13612

Submetido em: 11/07/2021

Revisões requeridas em: 09/08/2021

Aprovado em: 10/09/2021

Publicado em: 21/10/2021 